\title{
USING THE MILITARY GEOGRAPHICAL INSTITUTE PHOTOGRAMMETRIC DOCUMENTATION ARCHIVE DATA FOR SCIENTIFIC AND OTHER RESEARCH - THE NECESSITY AND IMPORTANCE OF DIGITIZATION
}

\author{
Saša Bakrač', \\ Zlatan Milonjić1, \\ Dejan Đorđević, \\ Zoran Srdić, \\ Slaviša Tatomirović ${ }^{1}$ \\ ${ }^{1}$ Military Geographica Institute, \\ Belgrade, Serbia
}

\begin{abstract}
:
The usage of aero photogrammetric methods in spatial data processing can provide important researching information, such as: soil erosion or phenomena of landslides, changes in forests and other vegetation, etc. The comparative analysis of archive aerial photogrammetrical images (API) and the latest aerial recording sessions can acquire information about the nature and trend of the problem, as well as the conclusions for taking preventive and corrective measures. This paper emphasizes the necessity and importance of the digitization of the Military Geographical Institute (MGI) photogrammetric documentation archive data in order to provide possibilities of using those archive data for scientific research.

This paper, apart from introduction and conclusion, consists of three parts: general information on MGI and photogrammetric documentation archive; general information on analog to digital API data conversion process; the necessity and importance of the MGI photogrammetric documentation archive digitization.
\end{abstract}

Keywords:

Military Geographical Institute, aerial photogrammetrical images, photogrammetric documentation archive, digitizing, spatial analysis.

\section{INTRODUCTION}

The main objective of this paper is to represent for scientific and other research the possibility of MGI photogrammetric documentation archive data usage to scientific and general public. In addition to the main objective, the paper aims to draw attention to necessity and importance of archive digitization. It is believed that archive digitization would provide a better basis for protection and use of archive items, which represents the initial hypothesis of this paper. The archive was established in 1950 and is comprised of the aerial images of the Republic of Serbia territory as well as the aerial images of the former republics of the Socialist Federal Republic of Yugoslavia territory. Considering quantity, the aforementioned archive is comprehensive, and according to the contents it includes a variety of aerial images products: analog aerial images (films), photograms, slides and other products derived from aerial images. The main and most important contents of the archive are aerial images.

It is common that modern research of numerous spatial items and for different purposes (scientific disciplines, businesses, etc.) require
Correspondence:

Saša Bakrač

e-mail:

sbakrac@yahoo.com 
consideration of the prior situation. Therefore, this archive provides both opportunity and benefits and can be used in numerous ways, especially for scientific purposes.

However, most of the archive items, especially analog aerial images, are in danger of complete disappearance, on the chemical basis because of the self-accelerating decomposition process. Therefore, implementation of archive digitization, apropos analog to digital form conversion is necessary as soon as possible.

\section{GENERAL INFORMATION ON MGI AND PHOTOGRAMMETRIC DOCUMENTATION ARCHIVE DATA}

The Serbian Armed Forces and the Ministry of Defence of the Republic of Serbia are supplied by MGI with geotopographical materials, primarily topographic maps. Moreover, other government organizations are supplied by MGI's products, as well as the private sector and individuals. In addition to general tasks, MGI is achieved through scientific research as an accredited institution - research and development institute. In the section of the general and scientific tasks MGI creates and archives the results of aerial recording sessions such as: aerial images (negatives and positives), photograms, slides, photo layouts and other product derived from aerial images. A photogram represents a pair of consecutive aerial images with longitudinal mutual overlap of $60 \%$; it is also referred to as a stereo pair (stereogram). A slide is a transparent image with tones which correspond to reality. A photo layout provides an overall recorded land oversight and objectively in detail represents the situation of mutual position of natural and artificial objects at the moment of recording.

Archive was established with the intention to preserve the most important results of aerial recording sessions, as well as corresponding data and recording records (location, scale, year, etc.).

Archive was established in 1950. Archive is located in the room which is, for better functionality, divided into two parts: working and storage part (Figure 1). The working part is intended for performing regular tasks within the archive competence (reception and issuance of aerial images, maintaining recording records, scanning, etc.) and there are stored photograms and slides. Aerial images are housed at storage (archive) part of aforementioned room. The room is air-conditioned and meets all formal requirements for operation and photogrammetric documentation prevention.

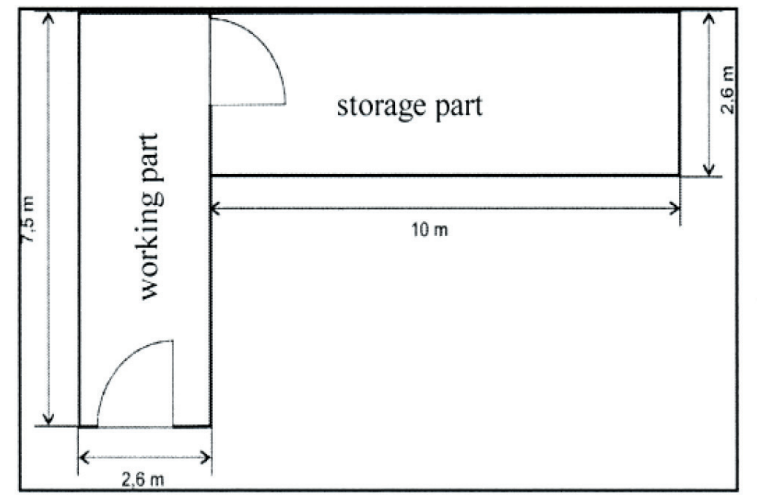

Fig. 1. Plan of the photogrammetric documentation archive data

The oldest film in archive is called Split, Omišs, ordinal 1 comprised of 34 aerial images and number of the first aerial image is 3844 . A significant part of the archive (more than $70 \%$ of the photogrammetric material) emanated as a result of photogrammetric survey of the former Socialist Federal Republic of Yugoslavia for the production purposes of topographic maps at the scale of 1:25.000 (TM25) and topographic maps of 1:50.000 (TM50).

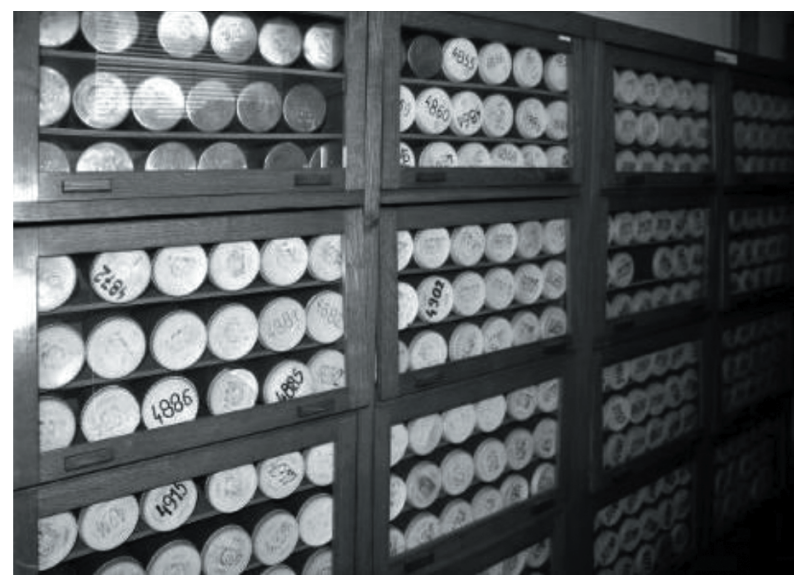

Fig. 2. An image of an archive part

Military Geographical Institute has been destined to keep permanently all negatives which were issued during realization of military tasks. Therefore, nowadays there is a possibility of comparing images of the same area which were recorded during different epochs. That can produce meaningful conclusions about certain phenomena and their changes over time. Furthermore, the old aerial images which have undergone the process of modern photogrammetric technologies can provide information 
about the area that could not be obtained at the time of their genesis and initial processing.

\section{GENERAL INFORMATION ON THE CONVERSION PROCESS OF ANALOG AERIAL IMAGES TO DIGITAL FORMAT}

Archive data conversion process from analog to digital format and their publication would be performed through several phases:

- Scanning of aerial images

- Designing, creation and input metadata

- Linking metadata to scanned aerial images using GIS tools and

- Web services publication.

In this case, it is optimal to use OGC 04-51 and OGC 04-52 standards [10], which explicitly include the scope of archiving and cataloguing of digital aerial images in accordance with the necessary web presentation requirements, searching and distribution, applying appropriate Open Web Service.

The most complex step in archive digitization is scanning of aerial images using specialized scanner at selected resolution [1].

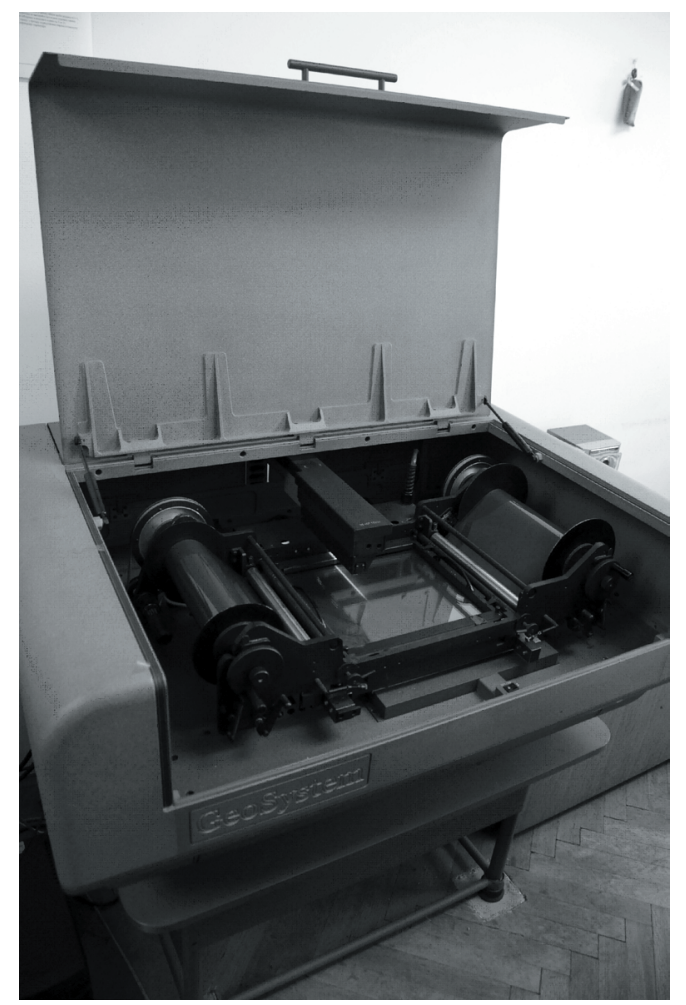

Fig. 3. An image of a type of photogrammetric scanner [4]
Further work would constitute an information system and database creation which would be comprised of alphanumeric data expanded with graphical data (scanned aerial images, flight plans, etc). This would establish data organization and both processes and information would be provided with useful information to beneficiaries - customers of information system.

The possibility of establishing a "live" system which could be updated, presented and connected to other systems in a real-time would be effectuated by metadata linking from database to GIS and WEB services.

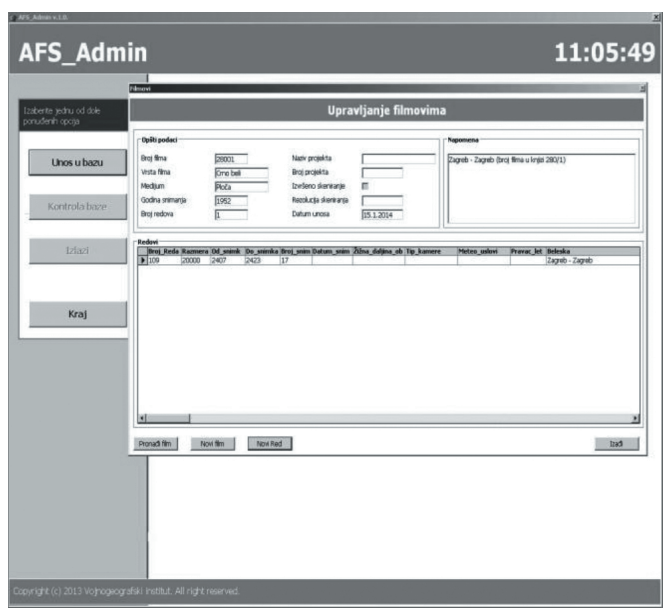

Fig. 4. An image of database window with options for aerial images management

\section{THE NECESSITY AND IMPORTANCE OF ARCHIVE PHOTOGRAMMETRIC DOCUMENTATION DIGITIZATION}

Considering the quantity and variety of archive items, the necessity of converting from analog to digital form is obvious. Likewise, in order to facilitate data searching there is a necessity to create relevant database. Furthermore, digitization provides conditions for better recording results preservation. The fact is that the film positives and negatives subject to the unstoppable process of losing individual properties and degradation over time. The largest parts of the archive items are negatives and they are especially sensitive. Obviously, negatives are more difficult for storing in analog than in digital format and require more storage space. Moreover, negatives are inflammable and are kept only in one sample, as opposed to digital format which can be easily multiplied and copies could be stored at different and remote locations.

The importance of archive digitization, especially the greater part which relates to aerial images is multifaceted. Firstly, it may be presented through faster searching, easier 
selection and download of required images, as well as the possibility of web services presentation. Therefore, archive digitization should create the basis for establishment of MGI's aerial survey and aerial images information system. Such information system will be easily accessible to the widest range of users, firstly searching and ordering-download. Further use of archive data, depending on requirements, can also be multifaceted. This paper emphasises the possibility and importance for the purposes of multidisciplinary character scientific research [2],[3],[6],[7],[8],[9].

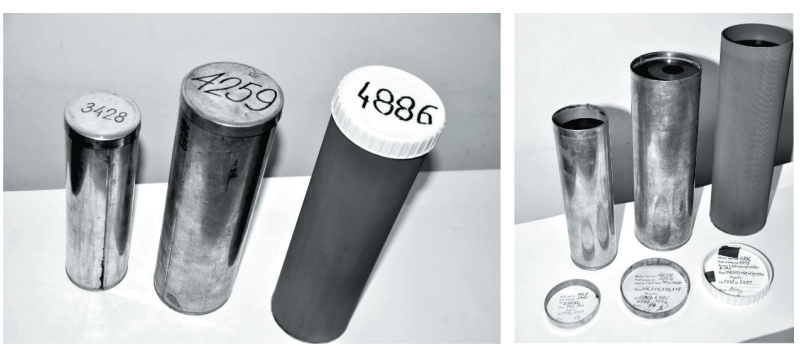

Fig. 5. Types of tubes for aerial images and lids labels

\section{CONCLUSION}

Using aerial survey methods and analysis of aerial images provides a good basis for a variety of geospatial research. The most interesting might be research intended for monitoring purposes: environmental, geographical factors, economic activities (tourism, forestry, water management, etc.). Compared to other geospatial data collection methods, including satellite imagery, undoubted are the advantages of this method. The most important are: full operational autonomy, data (image) quality, price and the use of images from substantially earlier recording periods. This type of researching is actual and present in many countries, especially the developed ones, as evidenced by a number of scientific papers published in prestigious journals. There is a universal understanding and internationally shared vision that national, scientific, cultural and historical significance is based on permanent preservation and retention of the aerial survey results. This importance is even greater considering the fact that MGI was the indigenous founder of photogrammetric survey methods application and since then has been a leader in its application (during a certain periods MGI had a sole aerial survey service). Therefore, the presentation of MGI's archive photogrammetric documentation, perceiving the importance and possibility of scientific and other purposes of using and consideration of the necessity of its digitization constitute the objective and represent the subject of this paper.

\section{REFERENCES}

Baltsavias E. (1994). Photogrammetric scanners -survey, technological developments and requirements, International Archives of photogrammetry and Remote Sensing. 32(Part B1), 44-50. DOI: 10.5194/ isprsarchives-XXXII-B1-44-1994

Crowley, J., Hubbard, B., \& Mars, J. (2003). Analysis of potential debris flow source areas on Mount Shasta, California, by using airborne and satellite remote sensing data. Remote Sensing of Environment. 87(2), 345-358. DOI: 10.1016/j.rse.2003.08.003

Fensham, RJ., Fairfax, RJ. (2002). Aerialphotography for assessing vegetation change: A review of applications and the relevance of findings for Australian vegetation history, Australian Journal of Botany. 50(4). 415-429. DOI: 10.1071/BT01032

GeoSystem (2010): Photogrammetric scanner "Deltascan-6":User's manual, Scientific product enterprise"GeoSystem", Vinnytsia Ukraine: GeoSystem.

Gruber, M., Leberl, F. (2001). Description and evaluation of the high quality photogrammetric scanner UltraScan 5000, ISPRS Journal of Photogrammetry Remote Sensing. 55. 313-329.

Harvey, KR., Hill, GJE. (2001). Vegetation mapping of a tropical freshwater swamp in the Northern Territory, Australia: A comparison of aerial photography, Landsat TM and SPOT satellite imagery. International Journal of Remote Sensing. 22(15). 2911-2925. DOI: 10.1080/014311601316958416

Huggel, C., Kääb, A., Haeberli, W., Teysseire, \& Paul, F. (2002). Remote sensing based assessment of hazards from glacier lake outbursts: A case study in the Swiss Alps. Canadian Geotechnical Journal. 39(2), 316-330. DOI: 10.1139/t01-099

Jauhiainen, S., Holopainen, M., Rasinmaki, A. (2007). Monitoring peatland vegetation by means of digitized aerial photographs. Scandanavian Journal of Forest Research. 22(2). 168-177. DOI: $10.1080 / 02827580701217620$

Laliberte, AS., Rango, A., Havstad, KM., Paris, JF., Beck, RF., McNeely, R., Gonzalez, AL. (2004). Object-oriented image analysis for mapping shrub encroachment from 1937 to 2003 in southern New Mexico. Remote Sensing of Environment. 93. 198-210. DOI:10.1016/j.rse.2004.07.011

Tomić, S. (2010). Standardizacija geoinformacija dobijenih fotogrametrijom $i$ daljinskom detekcijom (doktorska disertacija), Beograd: Univerzitet u Beogradu, Građevinski fakultet : Odsek za geodeziju i geoinformatiku. 